\title{
Noch einmal die Actinomycetenfrage!
}

\author{
Von \\ Dr. Gilbert. \\ Assistenzarzt der Augentlinik in Bonn.
}

Die Entgegnung Neukirch's ,Zur Actinomycetenfrage“ in Bd. XLVIII dieser Zeitschrift auf meine Arbeit, "Ueber Actinomyces thermophilus u.s.w." in Bd. XLVII veranlasst mich zu einer kurzen, der Sache selbst gewidmeten Bemerkung, wâhrend ich die mir persönlich gemachten Vorwürfe, wie mangelhafte Methodik und Technik sowie unzureichendes Mikroskopiren, getrost der Beurtheilnng anderer Untersucher der Actinomyceten überlasse.

Ich selbst habe jegliche Anwendung botanischer Fachausdrücke für die verschiedenen Wuchs- oder Dauerformen der Actinomyceten vermieden, weil keine vollkommene Analogie mit den Verhältnissen bei Fadenpilzen besteht. Nun sind ron Saurageau und Radais die an und für sich einwandsfreien Termini der Segmentation und der Fragmentation für die Actinomyceten eingeführt und von Kruse wurde ihr Unterschied folgendermaassen scharf präcisiert:

„Während die genannte Theilungsart in alten Culturen mehr oder weniger unregelmässig erfolgt and deshalb als Fragmentation bezeichnet werden mag, kommt es an der Oberfläche der Streptothrixculturen schon früh zu einer regelmässigen Theilung, zur Segmentation. Dieselbe geht von den . . . sich in die Luft erhebenden Fäden des Mycels aus und führt zur Bildung kettenartig an einander gereihter, gleichmässig runder Elemente. Man kann die letzteren als ... Sporen bezeichnen."

Dieser allgemein angenommenen Terminologie folgt auch LachnerSandoval, der in demselben. Institut, aber früher als Neukirch, gearbeit hat. Es heisst S. 40: „Die Fragmentation ist also, im Gegensatz 
zur später zu beschreibenden Segmentation oder Sporenbildung, ein Zerfall des Protoplasmas innerhalb der Zellmembran in verschieden grosse und oft unregelmässige Stücke"; und weiter wird, die Segmentation oder Sporenbildung betreffend gesagt, (S. 43), „dass die langsame Austrocknung sie begünstigt. . . . Die unbehinderte Luftzufuhr ist ebenfalls ein begünstigender Factor, denn die Sporenbildung findet fast nur an den Lufthyphen, auf den oberfächlichen Colonieen der Culturen in Flüssigkeiten am uppigsten ... statt."

Die Resistenzversuche Lachners (S. 46 bis 47 ) stimmen mit denen anderer Untersucher, wie Vincent, Domec und Verfasser überein: die vegetativen Massen sterben nach 5 Minuten lang währender Erwärmung auf $65^{\circ} \mathrm{ab}$, die aus Segmentation herrorgehenden Sporen erst bei 75 bis 80". „Wir sehen also," mit Lachner's Worten, „einen Widerstandsunterschied zwischen Impfmassen mit und ohne Sporen, der $15^{\circ}$ beträgt. $\mathrm{Ob}$ gleich dieser Unterschied sehr gering ist im Verhältniss zu den sporenbildenden Bakterien, so ist er hinreichend, um die Sporennatur jener runden Zellen, die durch die Segmentation an Lufthyphen entstehen, rom physiologischen Standpunkt aus und im Gegensatz zu den Fragmentationsproducten der vegetativen Fäden darzuthun."

Neukirch will nun die Bezeichnung Segmentation fallen lassen, weil der von Sauvageau und Radais sowie Lachner beschriebene Vorgang der Segmentation im Wesentlichen mit der Oidiensporenbildung der Botaniker übereinstimme (S. 29 bis 30 ).

Demnach sollte man erwarten, dass Neukirch für die Segmentation der Lufthyphen, also auch auf dem kreidigen Belag der Kartoffel, welche, wie oben hervorgehoben, die resistenten Sporen enthalten, den Namen der Oidiensporenbildung einführe. Das ist nun aber keineswegs der Fall; denn er sagt auf S. 40: es ,finden sich in der Regel beim Untersuchen des Bodensatzes ${ }^{1}$ einige Tage alter B-culturen meist breitere Fäden und unter ihnen solche, die von den bis jetzt besprochenen Elementen verschieden sind. Ihr ganzer Inhalt ist nämlich durch einfache Querwände, . .., in lauter (fertile) inhaltführende Stücke zerlegt. In einem solchen Faden hat nach früher gegebener Definition Oidientheilung stattgefunden." Die Elemente dieses Bodensatzes sind nun nach Neukirch weniger resistent, wie auch Levy ${ }^{2}$ hervorhebt, dass ,der Bodensatz mit seinen Fäden und seinen Oidiensporen bereits bei $60^{\circ}$ nach derselben Zeit (5 Min.) zu Grunde gingen" (S. 22).

\footnotetext{
1 Von mir gesperrt gedruckt.

${ }^{2}$ Levy, Centralblatt für Bakteriologie Bd. XXXIII.
} 
Somit.werden die Oidiensporen der Botaniker einmal den nach Lachner erst bei 75 bis $80^{\circ}$ absterbenden Segmentationssporen der Lufthyphen, das andere Mal den bei 60 bis $65^{\circ}$ zu Grunde gehenden Elementen des Bodensatzes gleichgestellt.

Andererseits wendet Lery mit Neukirch für die resistenzfähigeren Elemente an der Oberfäche den Namen „Fragmentationssporen“ an, so sagt er S. 21: „Auf der Oberfläche der Bouillonculturen und im hängenden Tropfen dagegen geht die Entstehung der Dauerformen nach einem besonderen Vorgange vor sich. .... Wir meinen die Fragmentation" und auf S. 22: „Jedenfalls besitzen die Fragmentationssporen eine erheblichere Widerstandsfähigkeit als die Oidiensporen." Bis dahin verstand man unter Fragmenten gerade die weniger resistenten Formen, die meist in der Tiefe des Substrats gebildet werden.

Eine solche vollkommene Vertauschung der üblichen Termini ist nicht statthaft und führt, wie ich in meiner oben citirten Arkeit hervorgehoben habe, nur zur Verwirrung. 